\section{Intraductal ultrasonography-directed endoscopic retrograde biliary drainage without fluoroscopy}
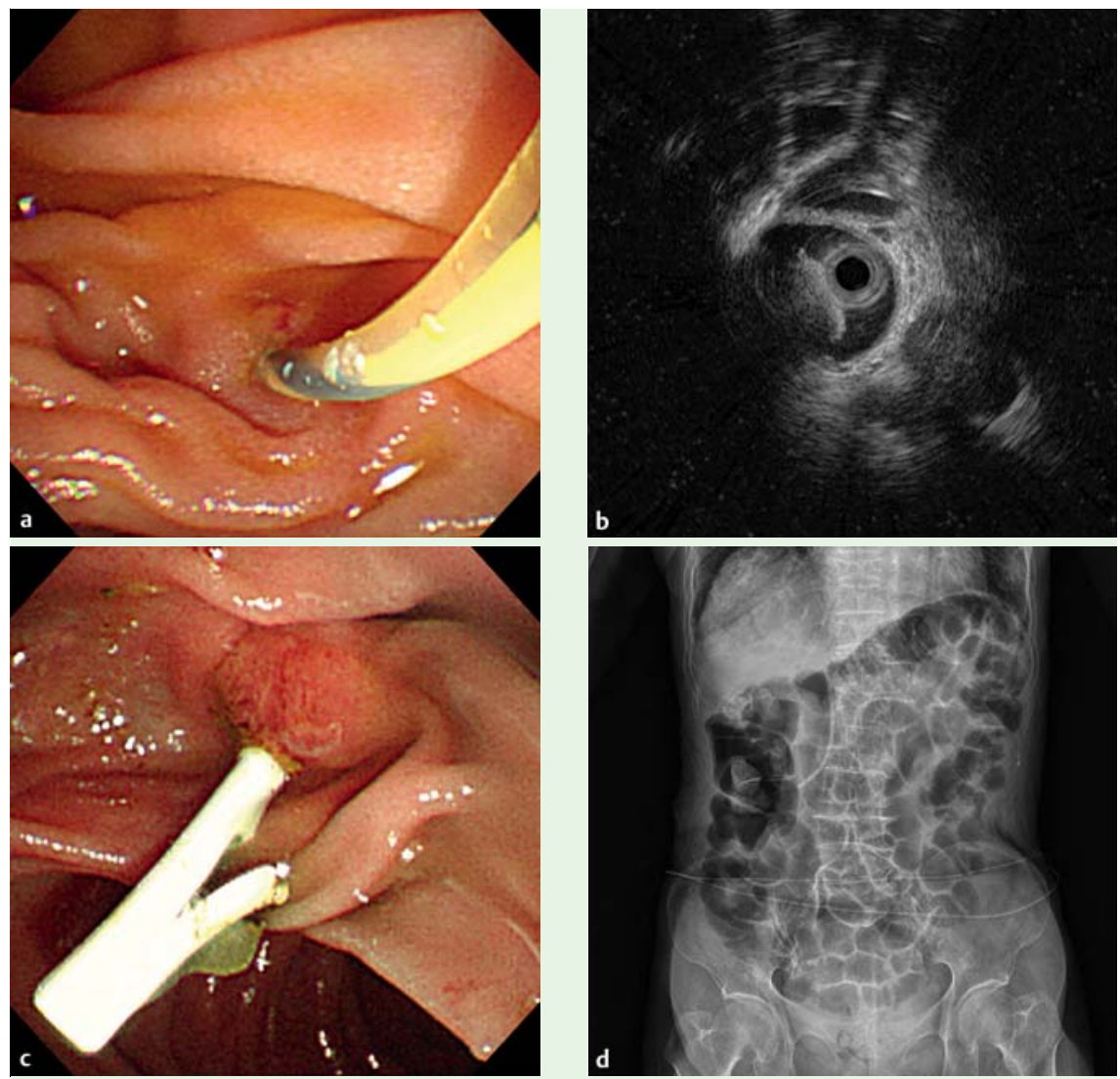

Fig. 1 Intraductal ultrasonography (IDUS)-directed endoscopic retrograde biliary drainage (ERBD) without fluoroscopy. a Bile aspiration after biliary cannulation. $\mathbf{b}$ IDUS views of a stone in the common bile duct. $\mathbf{c}$ Placement of stent for ERBD using IDUS without fluoroscopy. $\mathbf{d}$ Plain abdominal radiograph after ERBD insertion.

Common bile duct (CBD) stones may cause septic shock and lead to life-threatening conditions [1]. Endoscopic sphincterotomy (EST) and stone removal is an accepted method for the treatment of CBD stones [2]. EST has the potential to cause bleeding in patients with a bleeding risk. However, endoscopic retrograde biliary drainage (ERBD) can be performed effectively and safely without EST in these patients. ERBD has been performed under fluoroscopy, resulting in a relatively long duration of radiation exposure $[3,4]$. Intraductal ultrasound (IDUS) provides realtime cross-sectional imaging within the bile duct. IDUS can be performed without fluoroscopy. Therefore, IDUS-directed ERBD can be used to reduce the time of radiation exposure for both examiners and patients. This report describes IDUSdirected ERBD with a plastic stent without fluoroscopy in patients with a risk of bleeding.
A total of nine IDUS-directed ERBD procedures without fluoroscopy were performed. All procedures were performed using a standard side-viewing duodenoscope (TJF-160F; Olympus, Tokyo, Japan). After cannulation with a 0.035 -inch guidewire (Jagwire; Boston Scientific, Natick, Massachusetts, United States), the "bile aspiration" technique was used to indicate bile duct cannulation ( Fig. 1a) [5]. A 2.0-mm IDUS probe with a frequency of 20-MHz (UM-G20-29R; Olympus) was advanced over the guidewire into the bile duct. After images of ductal anatomy and lesions had been obtained ( $\bullet$ Fig. 1 b), the insertion length of the IDUS probe, from the papilla of Vater to the lesions, was used to determine the length of plastic stent (Percuflex DUODENAL BEND Biliary Stent; Boston Scientific) that was required. The plastic stent for ERBD was inserted over the guidewire and placed in the correct position after withdrawal of the IDUS probe ( $\bullet$ Fig. 1 c). The location of the ERBD stent was confirmed by plain radiography (๑ Fig.1 d).

Successful intubation of the papilla, selective CBD cannulation, and appropriate ERBD were achieved in all patients (9/9, $100 \%$ ). No complications were observed in any patient.

Endoscopy_UCTN_Code_TTT_1AS_2AD

Competing interests: None Ji-Myoung Lee ${ }^{1}$, Chang-Hwan Park' ${ }^{1}$,
Soo-Jung Rew ${ }^{2}$, Ha-Na Kim ${ }^{1}$, Ho-Jun
Lee $^{1}$, In-Hyung Park ${ }^{1}$, Seon-Young Park ${ }^{1}$

${ }^{1}$ Department of Internal Medicine, Chonnam National University Medical School, Gwangju, Korea

2 Department of Internal Medicine, Gwangju Christian Hospital, Gwangju, Korea

\section{References}

$1 \mathrm{Lu}$ J, Guo CY, Xu XF et al. Efficacy of intraductal ultrasonography in the diagnosis of nonopaque choledocholith. World J Gastroenterol 2012; 18: 275-278

2 Jiang XW, Tang SH, Yang JQ et al. Ultrasoundguided endoscopic biliary drainage: a useful drainage method for biliary decompression in patients with biliary obstructions. Dig Dis Sci 2014; 59: 161 - 167

3 Tsapaki V, Paraskeva KD, Mathou $N$ et al. Patient and endoscopist radiation doses during ERCP procedures. Radiat Prot Dosimetry 2011; 147: $111-113$

4 Lorenzo-Zuniga V, Alvarez MA, Moreno de Vega $V$ et al. Predictive factors of radiation dose in ERCP: a prospective study in 2 tertiary centers. Surg Laparosc Endosc Percu$\tan$ Tech 2013; 23: 266-270

5 Siegel JH, Rodriquez R, Cohen SA et al. Endoscopic management of cholangitis: critical review of an alternative technique and report of a large series. Am J Gastroenterol 1994; 89: $1142-1146$

\section{Bibliography}

DOI http://dx.doi.org/

10.1055/s-0034-1377587

Endoscopy 2014; 46: E495

(c) Georg Thieme Verlag KG

Stuttgart · New York

ISSN 0013-726X

\section{Corresponding author}

\section{Chang-Hwan Park, MD, PhD}

Department of Internal Medicine

Chonnam National University Medical School

42 Jebongro, Dong-gu

Gwangju, 501-757

Korea

Fax: +82-62-2258578

p1052ccy@hanmail.net 